\title{
Small-Size Meandered Loop Antenna for WLAN Dongle Devices
}

\author{
Wen-Shan Chen, Chien-Min Cheng, Da-Huei Lee, Chun-Lin Ciou, \\ Wei-Syun Sin, and Guang-Yuan Cai \\ Department of Electronic Engineering, Southern Taiwan University of Science and Technology, Tainan 710, Taiwan \\ Correspondence should be addressed to Wen-Shan Chen; chenws@mail.stust.edu.tw
}

Received 14 September 2013; Accepted 7 October 2013; Published 13 February 2014

Academic Editor: Shoou-Jinn Chang

Copyright (c) 2014 Wen-Shan Chen et al. This is an open access article distributed under the Creative Commons Attribution License, which permits unrestricted use, distribution, and reproduction in any medium, provided the original work is properly cited.

\begin{abstract}
This paper proposes a loop-type USB dongle antenna, which is fabricated on a $1.6 \mathrm{~mm}$ thick FR-4 substrate for WLAN band systems. The front side of substrate consists of a 50-ohm coaxial line and a multiarm monopole antenna, while the back side has a meandered loop antenna connected to the ground by two via holes. The meandered loop resonates half-wavelength mode at about $2.4 \mathrm{GHz}$ and its higher modes. The higher modes excited by the multiarm monopole form the $5.2 \mathrm{GHz}$ frequency band. The bandwidth of the antenna covers the IEEE802.11 a/b/g WLAN applications. The overall dimensions of the antenna of $30 \times 13.75 \times 1.6 \mathrm{~mm}^{3}$ with an antenna area of $7.5 \times 13.75 \mathrm{~mm}^{2}$ and a planar structure are exactly suitable for applying in dongle devices. The measured results of radiation patterns, antenna gain, and radiation efficiency are also proposed and discussed in the paper.
\end{abstract}

\section{Introduction}

In recent years, wireless communication systems have been rapidly developed for mobile phone, GPS, RFID, and WLAN applications [1]. One important feature for wireless devices is being portable that attracts consumers' interests for its convenience. Among the wireless systems, WLAN USB dongle used in the internet and Wi-Fi system is the most convenient device for its smallest dimensions. In practice, IEEE 802.11 standards for WLAN consist of $2.4 \mathrm{GHz}(2.4-$ $2.484 \mathrm{GHz}) 5.2 \mathrm{GHz}(5.15-5.35 \mathrm{GHz})$ frequency bands; therefore, the antenna used in WLAN devices needs to cover these frequency bands. Many small printed antennas have been proposed for WLAN USB dongle. In the published articles [2-5], the width of antennas are $10 \mathrm{~mm}$ and these antennas are for $2.4 \sim 5.35 \mathrm{GHz}$ application. In this design, a width of $13.75 \mathrm{~mm}$ loop antenna including application bands (IEEE $802.11 \mathrm{a} / \mathrm{b} / \mathrm{g}$ ) will be proposed. Antenna portion of the antenna is minimal compared to the reference design. Smallsize antenna can design specifications suitable and used in many applications and good production. Production of the original size of $30 \times 13.75 \times 1.6\left(\mathrm{~mm}^{3}\right)$ is suitable for smallsized USB Dongle devices.

\section{Results and Discussion}

The geometry of the proposed antenna is shown in Figure 1. The antenna is fabricated on an FR4 substrate with a thickness of $1.6 \mathrm{~mm}$, a relative permittivity of 4.4 , and a loss tangent of 0.024 . And the detailed dimensions of the proposed antenna are also listed in Table 1 . The overall dimension of $30 \times$ $13.75 \mathrm{~mm}^{2}$ contains an antenna portion of $7.5 \times 13.75 \mathrm{~mm}^{2}$ and a ground plane of $22.5 \times 13.75 \mathrm{~mm}^{2}$. And a $50 \mathrm{ohm} \mathrm{mini}$ coaxial-line is used for RF signal input. In our design, two vias (via hold size radius $0.5 \mathrm{~mm} \times$ height $1.6 \mathrm{~mm}$ ) to connect the ground and back loop strip is used. By optimizing the antenna parameters, both the simulated and measured return losses meet the WLAN application bands ( 2.4 to $2.484 \mathrm{GHz}, 5.15$ to $5.35 \mathrm{GHz}$ ) as shown in Figure 2. The measured and simulated return losses have good agreements to ensure the reliability of the design. The simulated results are obtained through HFSS simulation software.

The multiline monopole and the meandered loop form a coupled-fed loop antenna structure. In antenna's lower operation bands, the meandered loop produces a halfwavelength fundamental band at $2.4 \mathrm{GHz}$. And the higher operation bands are produced by the high order modes of 
TABLE 1: Detailed dimensions of the proposed antenna.

\begin{tabular}{|c|c|c|c|c|c|c|c|c|c|c|c|c|c|c|c|c|c|c|c|}
\hline Parameter & $L$ & $L 1$ & $L 2$ & $L 3$ & $L 4$ & $L 5$ & $L 6$ & L7 & $L 8$ & $L 9$ & $L 10$ & $L 11$ & $L 12$ & $L 13$ & $L 14$ & $W$ & $W 1$ & $W 2$ & $W 3$ \\
\hline Unit (mm) & 30 & 22.5 & 4.95 & 1.3 & 1.2 & 2.9 & 1.7 & 2.5 & 8.6 & 9 & 6.5 & 4.1 & 3.3 & 3.9 & 2.5 & 13.75 & 1 & 2 & 1 \\
\hline
\end{tabular}

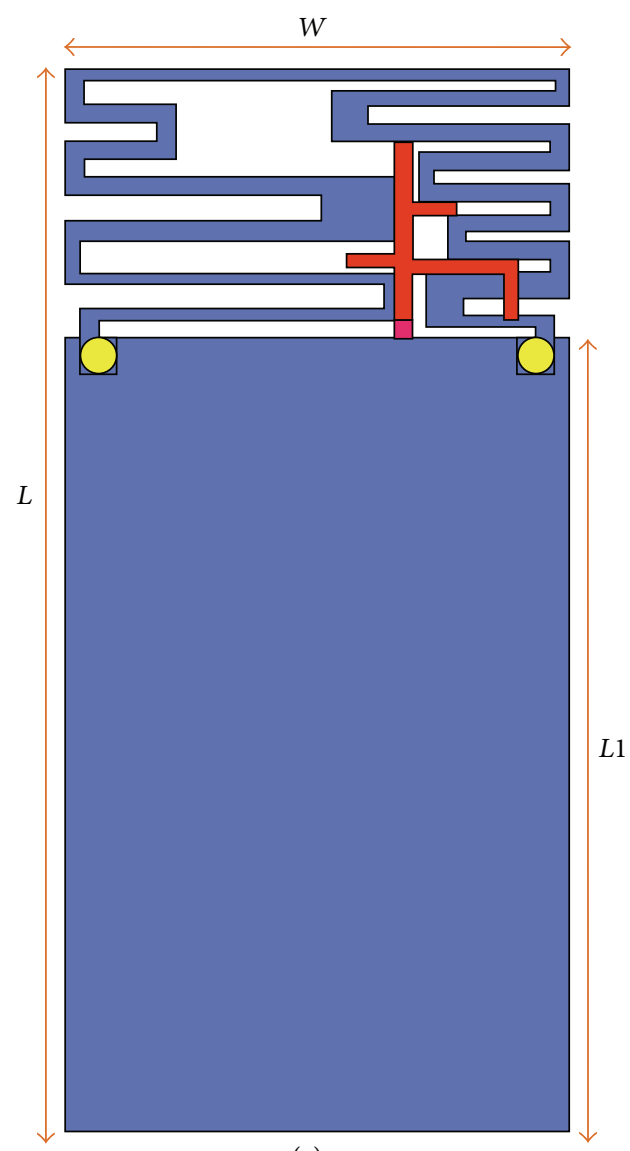

(a)

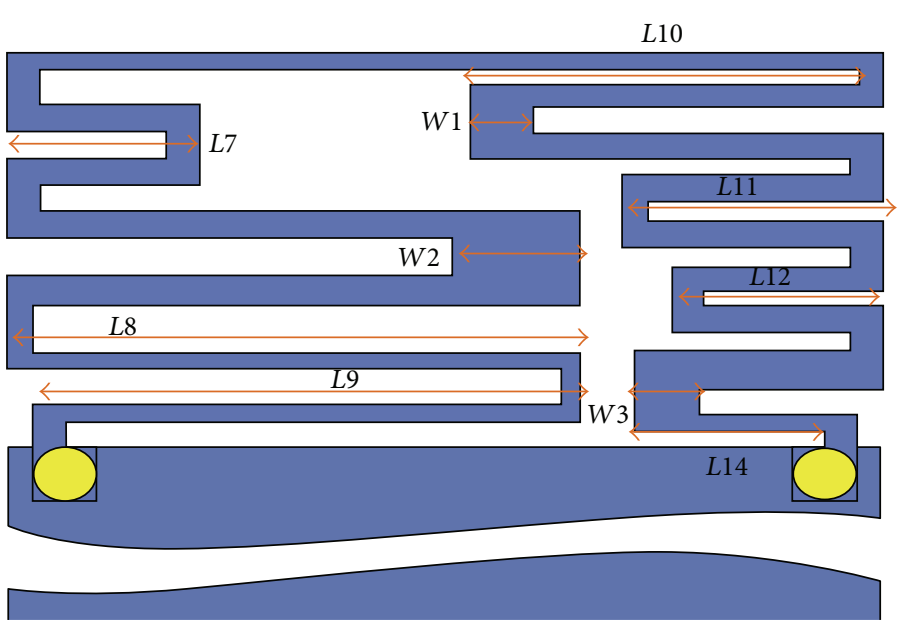

(b)

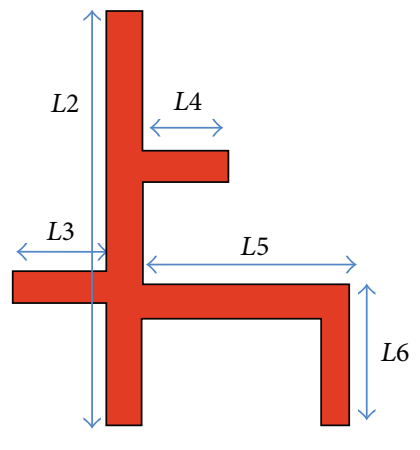

(c)

FIGURE 1: (a) Overall antenna; (b) on the back loop structure; (c) the multiline monopole; (d) antenna specification.

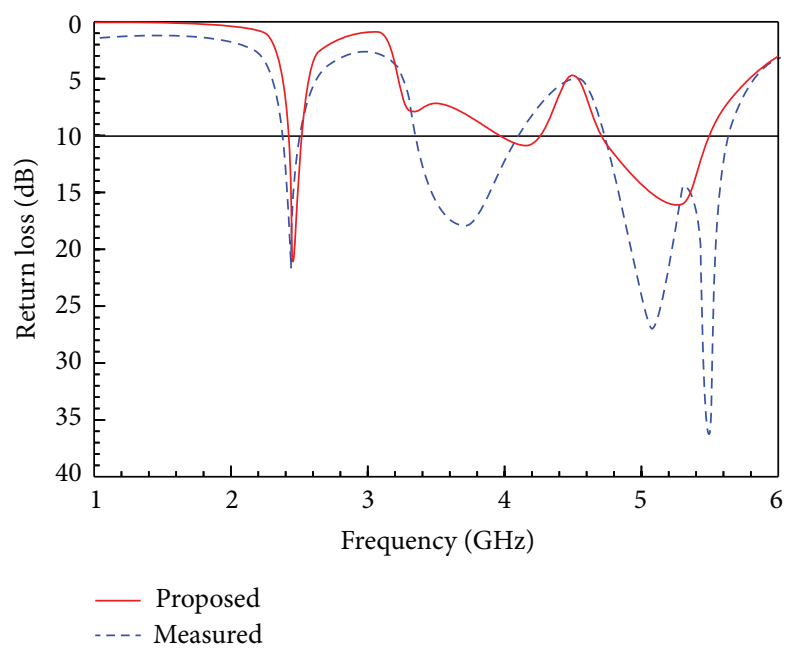

FIGURE 2: Simulated and measured return losses of the proposed antenna. 


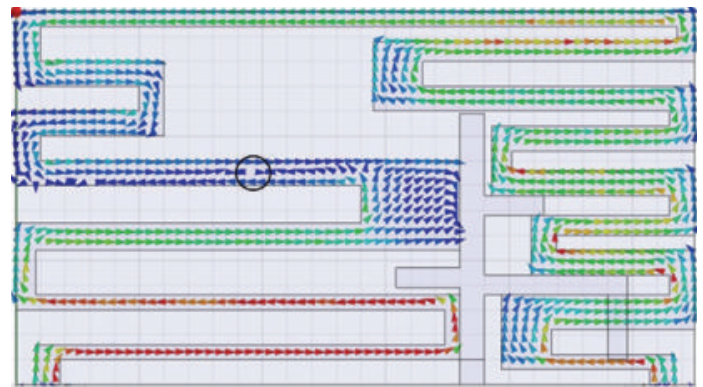

(a)

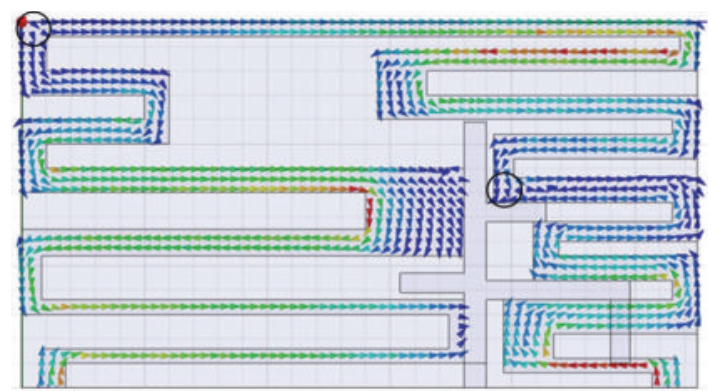

(b)

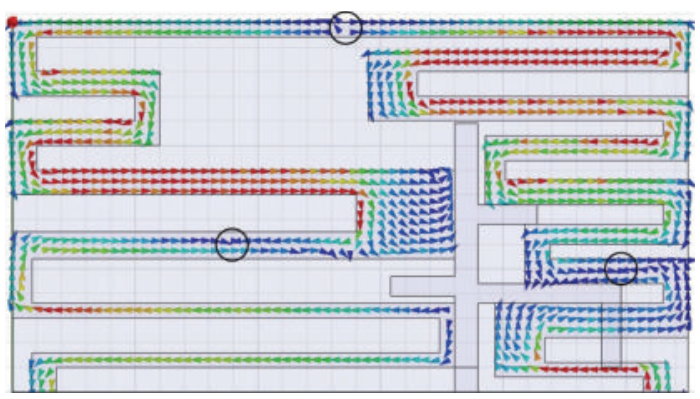

(c)

FIGURE 3: Simulated surface current distribution on the proposed antenna's (a) $2.45 \mathrm{GHz}$, (b) $4.13 \mathrm{GHz}$, and (c) $5.25 \mathrm{GHz}$.
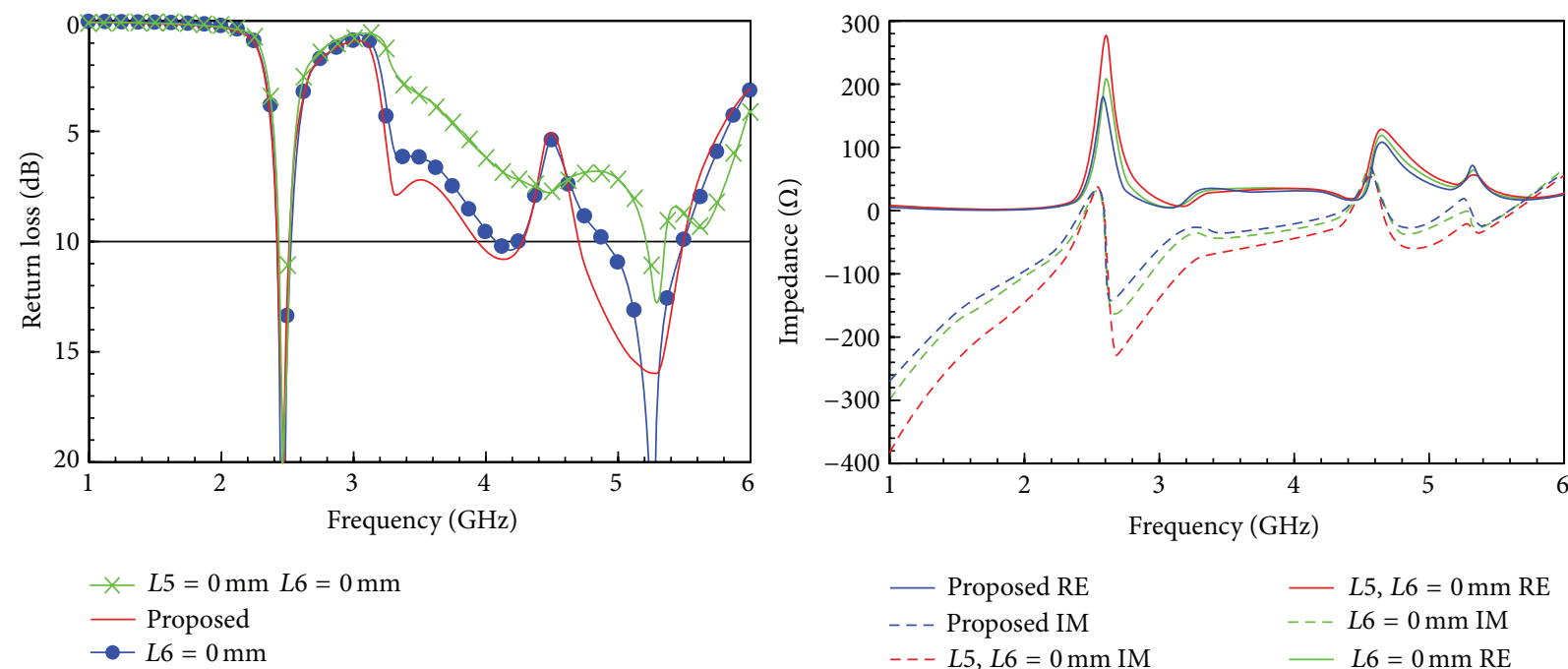

FIGURE 4: Simulated return losses and impedance of the proposed antenna with and without L5 and L6.

the loop. The simulated current distribution of the antenna at (a) $2.45 \mathrm{GHz}$, (b) $4.13 \mathrm{GHz}$, (c) $5.25 \mathrm{GHz}$ is shown in Figure 3. From the figures shown in Figure 3, It is indicated that the loop produces $0.5,1$, and $1.5 \lambda$ modes (at 2.45, 4.14, and $5.25 \mathrm{GHz}$ ).

Some parametric study of the antenna is also investigated in this paragraph. Figure 4 shows the simulated return losses and the impedance of the proposed antenna with and without L5 and L6. When without L5 and L6, the higher mode's impedance is not matched. Figure 5 shows the simulated return losses and the impedance of the proposed antenna with different lengths of L8 and L9. When the length of L9 is decreased, the proposed antenna excites lower mode at $2.4 \mathrm{GHz}$ to increase bandwidth of low operation band. Figure 6 shows the simulated return losses and the impedance of the proposed antenna with different lengths of L10. When the length of L10 equals $6.5 \mathrm{~mm}$, the two higher modes generate the best impedance matching in Figure 6. Figure 7 shows the simulated return losses and the impedance of the proposed antenna with different lengths of W2. We can find 

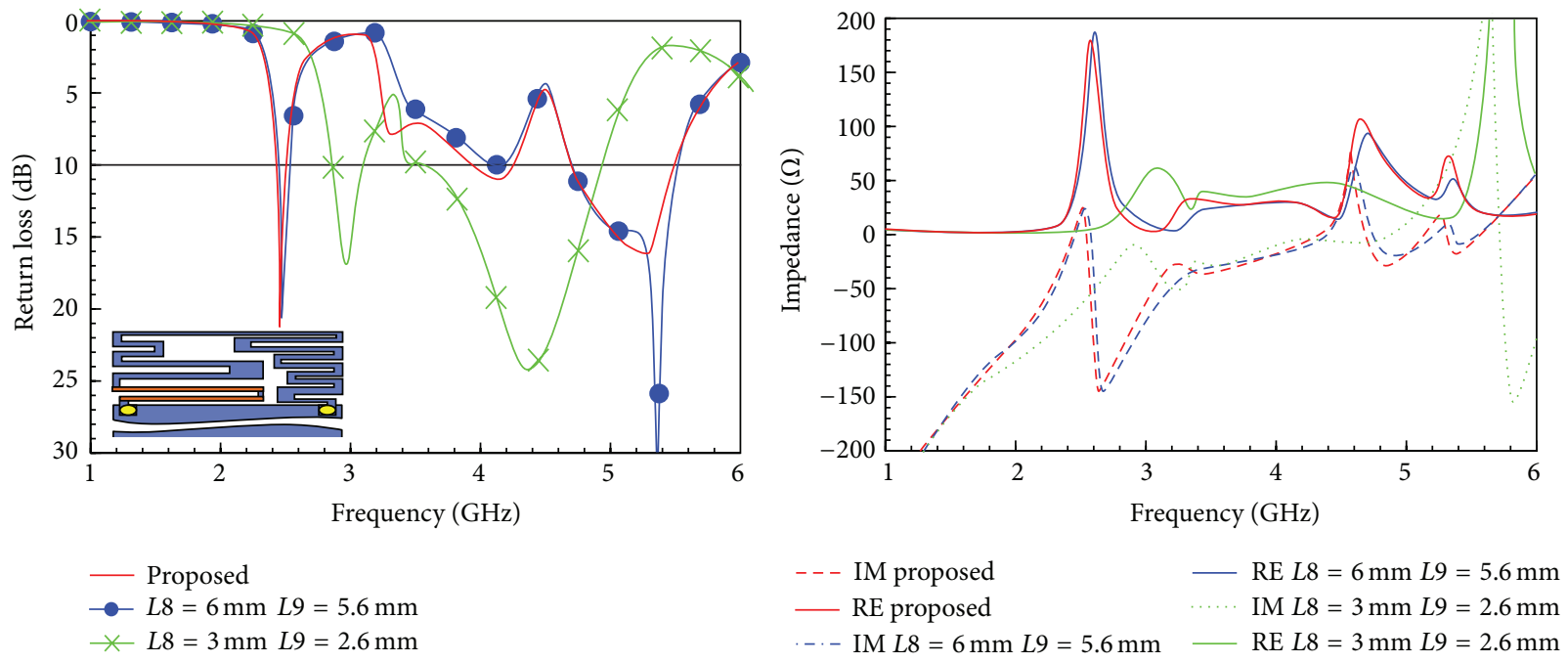

FIGURE 5: Simulated return losses and impedance of the proposed antenna for different lengths of L8 and L9.
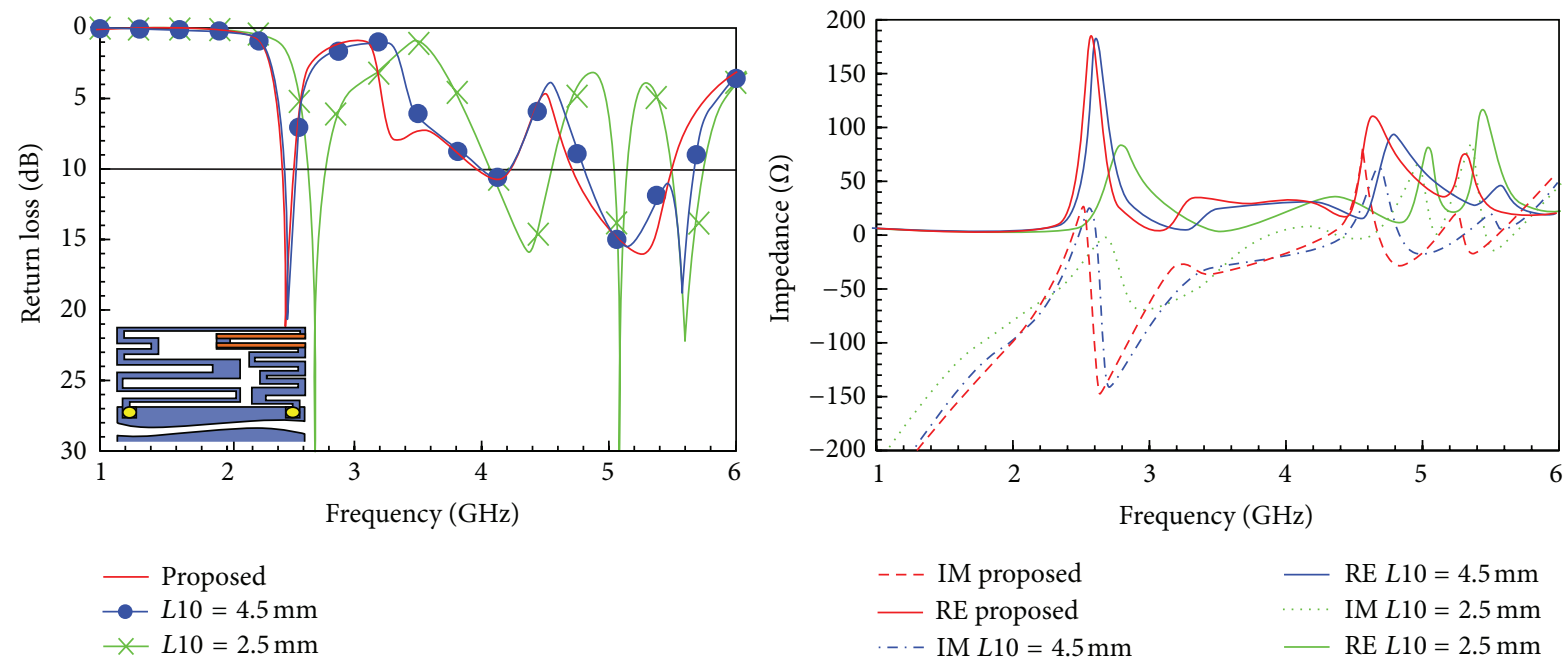

FIGURE 6: Simulated return losses and impedance of the proposed antenna for different lengths of L10.
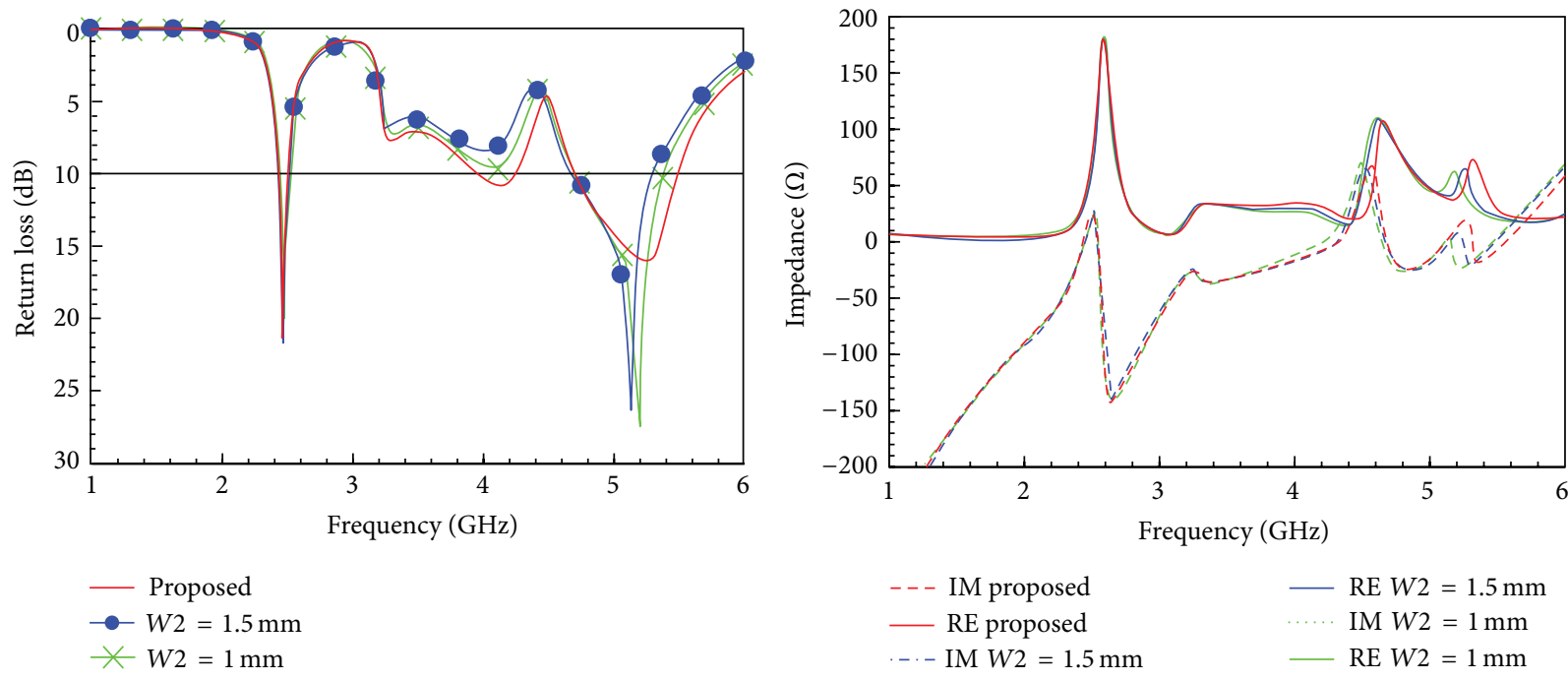

FIGURE 7: Simulated return losses and impedance of the proposed antenna for different lengths of W2. 

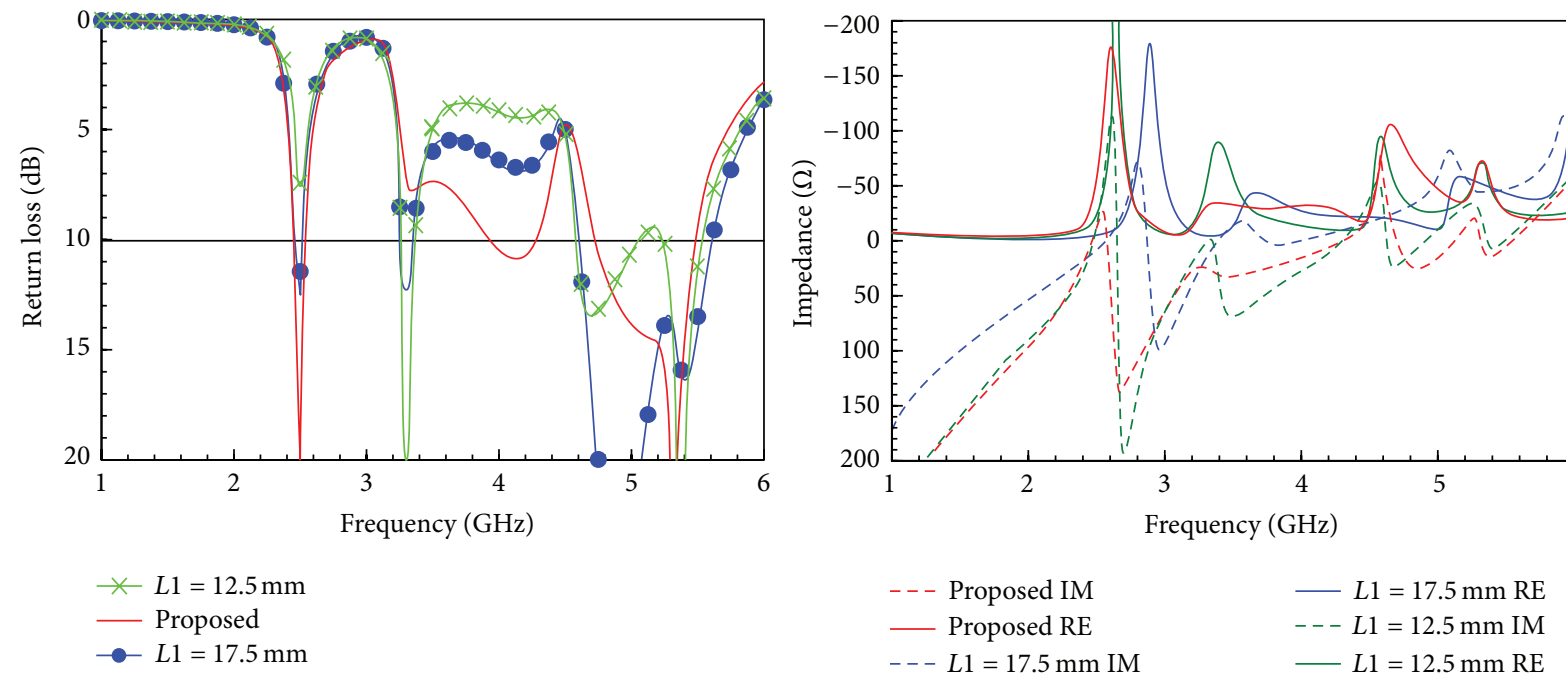

FIGURE 8: Simulated return losses and impedance of the proposed antenna of L1.
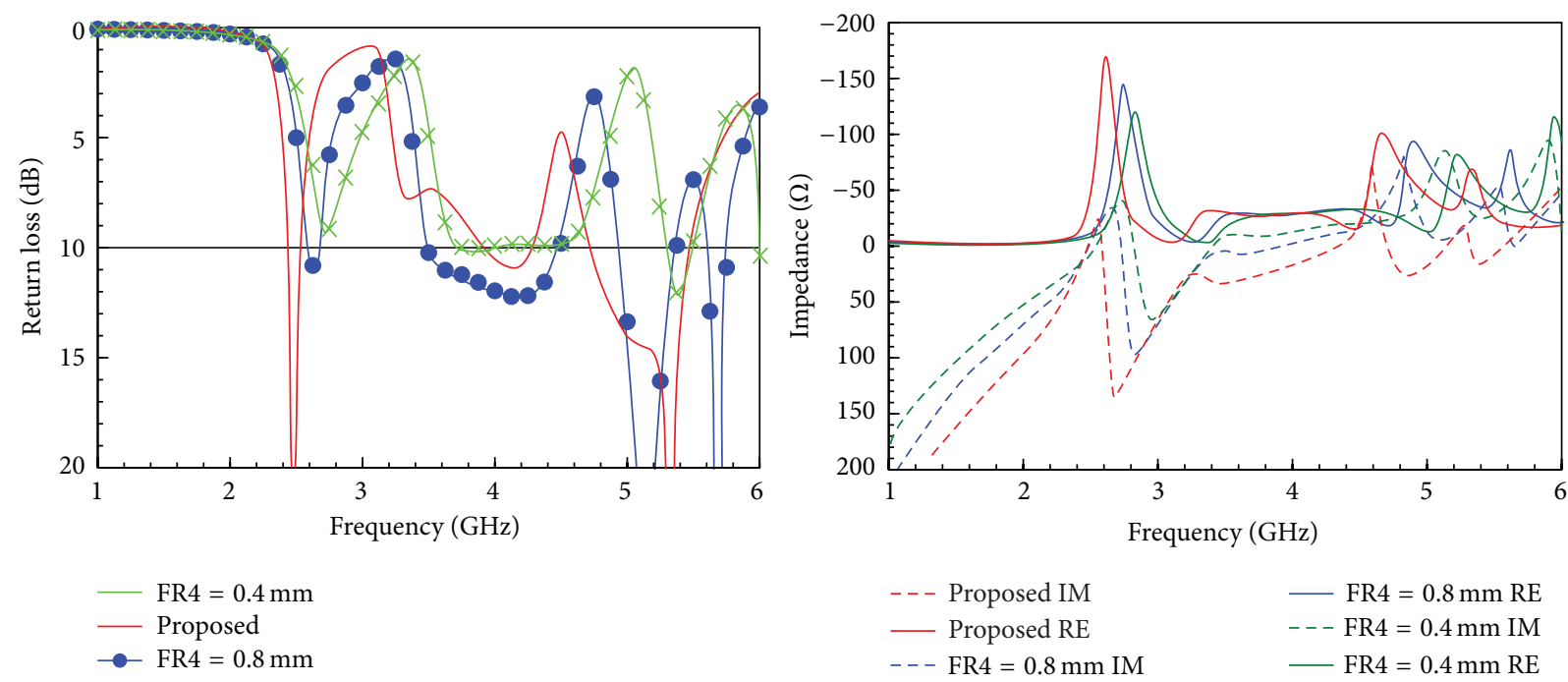

FiguRE 9: Simulated return losses and impedance of the proposed antenna of different thickness.

that the higher modes impedance is not matched when the length of W2 equal to $1.5 \mathrm{~mm}$. Figure 8 shows the simulated return losses and the impedance of the proposed antenna with different lengths of L1. When the length of the L1 varies from 12.5 to $22.5 \mathrm{~mm}$, the modes of loop are not changed too much; only the impedance changes. So we choose the system ground area length of $22.5 \mathrm{~mm}$. Figure 9 shows the simulated return losses and the impedance with different thickness of the substrate of the proposed antenna. The thickness of the substrate used in $1.6 \mathrm{~mm}$ is most suitable for our design.

The radiation performances of an antenna are important parameters for applications. The radiation patterns and efficiency of the antenna are measured in $3 \mathrm{D}$ chamber at Cheng Shiu University. Figures 10(a), 10(b), and 10(c) show the measured radiation patterns at 2.4, 5.15, and $5.35 \mathrm{GHz}$. Figure 10(a) shows the radiation pattern at $2.4 \mathrm{GHz}$ and the radiation pattern in $Y-Z$ plane is near omnidirectional characteristic. Figure 10(b) shows the radiation patterns at $5.15 \mathrm{GHz}$ and the radiation pattern in $Y-Z$ plane is also near omnidirectional characteristic. Figure 10(c) shows the radiation pattern at $5.35 \mathrm{GHz}$. Figure 10 shows the measured antenna gain and efficiency of the proposed antenna. In Figure 11(a), the measured antenna gains at 2.4 to $2.5 \mathrm{GHz}$ show a stable characteristic. The antenna gains are from 1.32 to $1.45 \mathrm{dBi}$ with a small variation of $0.13 \mathrm{dBi}$ and the radiation efficiency here is larger than 70\%. Figure 11(b) shows the measured antenna gains at 5.15 to $5.35 \mathrm{GHz}$ that present a stable characteristic. The antenna gains are from 2.1 to 

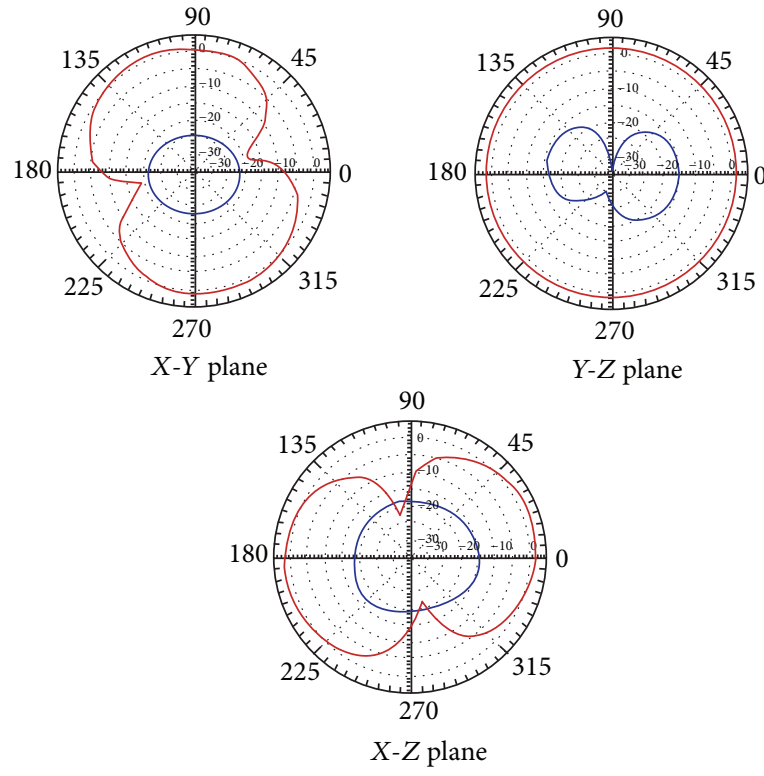

(a)

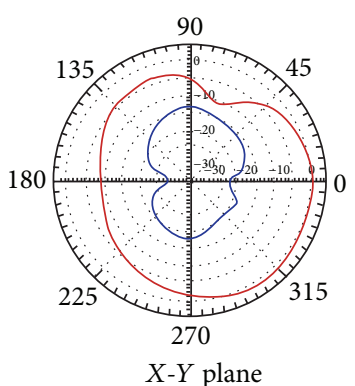

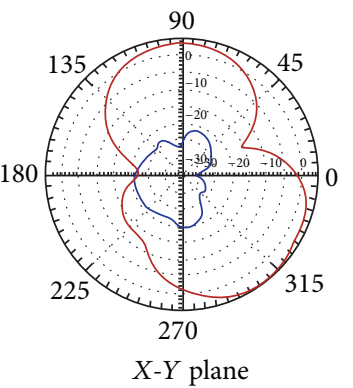
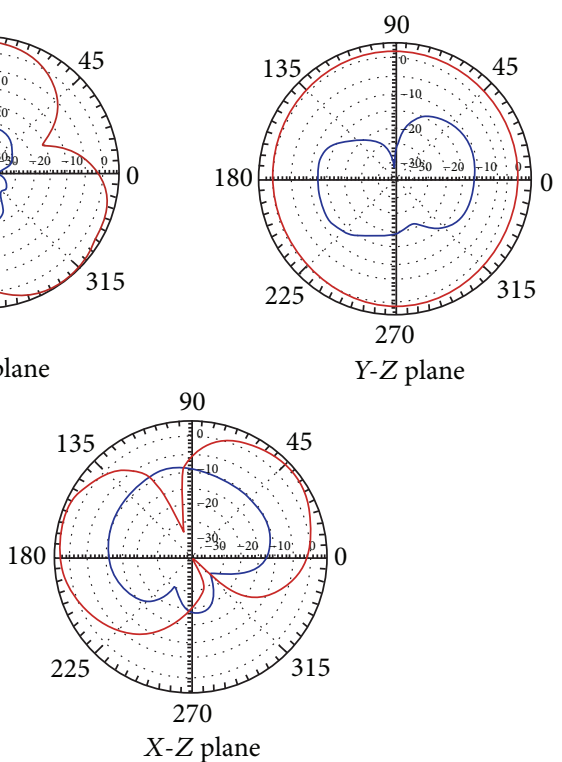

(b)
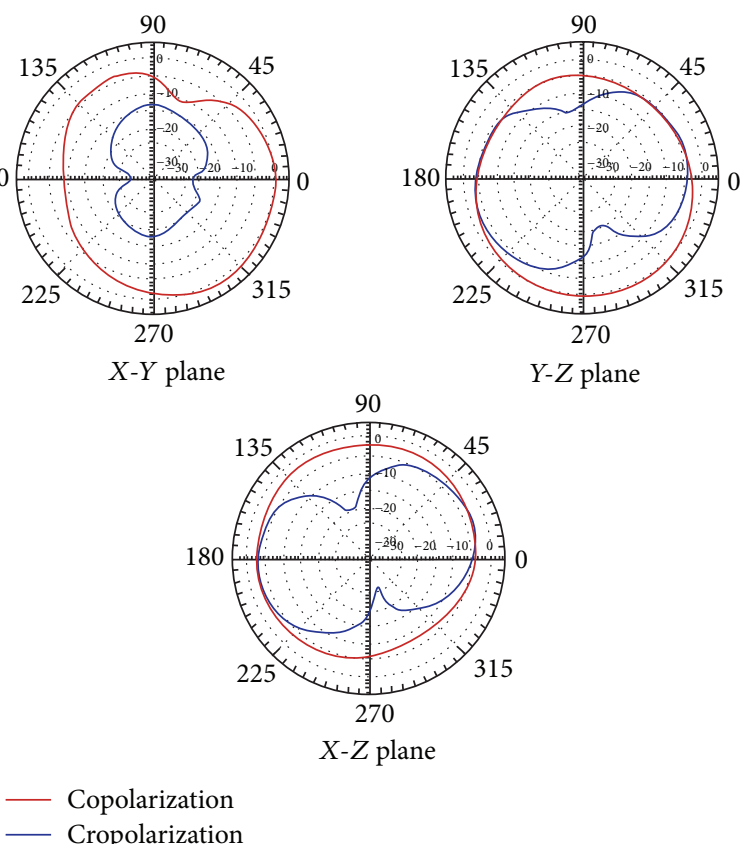

Y-Z plane

(c)

FIGURE 10: Measured radiation pattern of the proposed antenna at (a) $2.4 \mathrm{GHz}$ (b) $5.15 \mathrm{GHz}$ (c) $5.35 \mathrm{GHz}$.

$1.36 \mathrm{dBi}$ with a small variation of $0.74 \mathrm{dBi}$ and the radiation efficiencies from 5.15 to $5.35 \mathrm{GHz}$ are all larger than $60 \%$. The performances of the antenna are suitable for applying in portable devices with small size.

\section{Conclusions}

A small-size USB Dongle antenna for WLAN application has been proposed and verified. The operating frequency band is easily adjusted by changing antenna's dimensions. The measured and simulated impedance bandwidth can cover the band of $802.11 \mathrm{a} / \mathrm{b} / \mathrm{g}$ applications. To antenna's performances, the measured radiation patterns perform an omnidirectional feature. Both antenna gains within two frequency bands are stable and good for the application of dongle devices.

\section{Conflict of Interests}

The authors declare that there is no conflict of interests regarding the publication of this paper. 


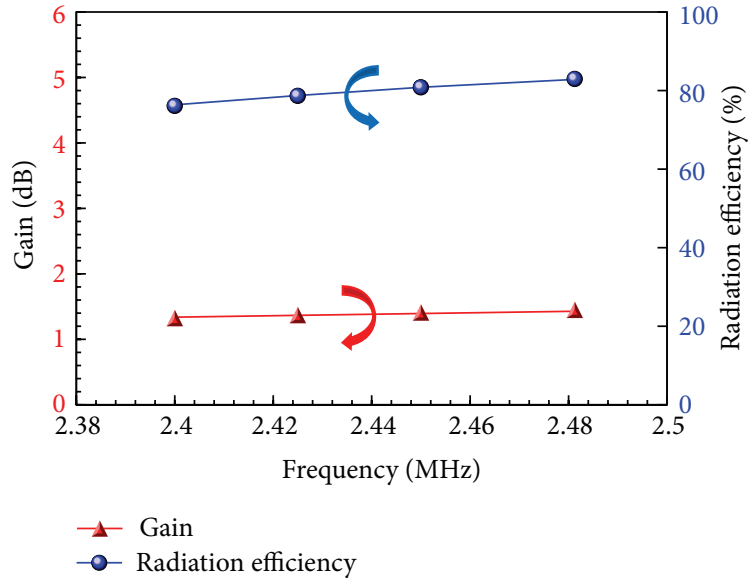

(a)

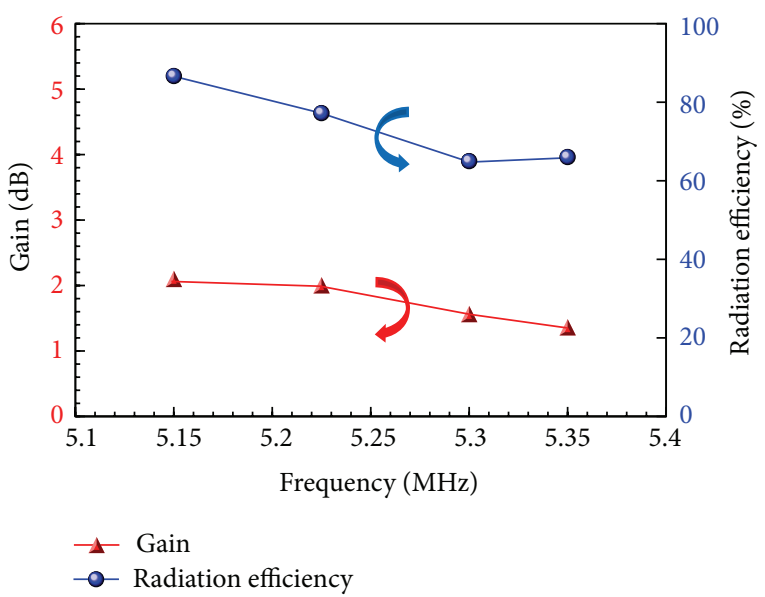

(b)

FIGURE 11: Measured antenna gain and efficiency at (a) $2.4-2.5 \mathrm{GHz}$ and (b) 5.15-5.35 GHz.

\section{Acknowledgments}

This work was supported by the National Science Council of Taiwan under Grant nos. of NSC 101-2632-E-218-001-MY3, NSC 102-2221-E-218-005, and NSC 101-2221-E-218-032. the authors would like to thank Professor F.S. Chang for help in measuring the radiation patterns and efficiency of the study.

\section{References}

[1] W.-S. Chen, Y.-T. Liu, and W.-H. Hsu, "Multi-frequency printed loop antenna for mobile phone application," in Proceedings of the IEEE International Symposium on Antennas and Propagation (APSURSI '11), pp. 1926-1928, July 2011.

[2] C. Chokchaiy, S. Chaimoolz, and P. Akkaraekthalin, "Miniaturized triple-band USB dongle antenna using loaded-fractal loop monopole with shorted loop and fractal loop resonator," in Proceedings of the 9th International Conference on Electrical Engineering/Electronics, Computer, Telecommunications and Information Technology (ECTI-CON '12), pp. 1-4, 2012.
[3] S. Chaimool, C. Chokchai, and P. Akkaraekthalin, "Multiband loaded fractal loop monopole antenna for USB dongle applications," Electronics Letters, vol. 48, no. 23, pp. 1446-1447, 2012.

[4] S. J. Jeong and K. C. Hwang, "Compact loop-coupled spiral antenna for multiband wireless USB dongles," Electronics Letters, vol. 46, no. 6, pp. 388-389, 2010.

[5] D. Kim, U. Kim, and J. Choi, "Design of a wideband internal monopole antenna for wireless USB dongle application," in Proceedings of the Asia-Pacific Microwave Conference (APMC '10), pp. 231-234, December 2010. 

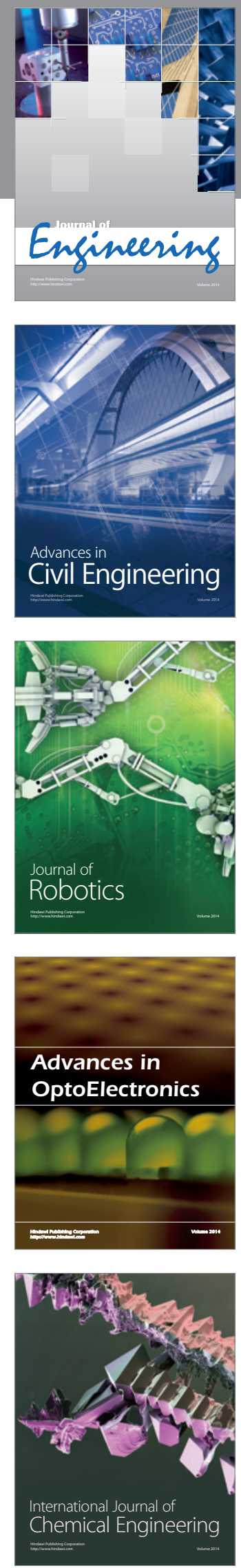

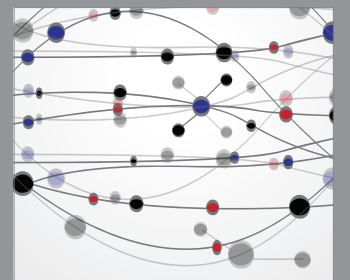

The Scientific World Journal
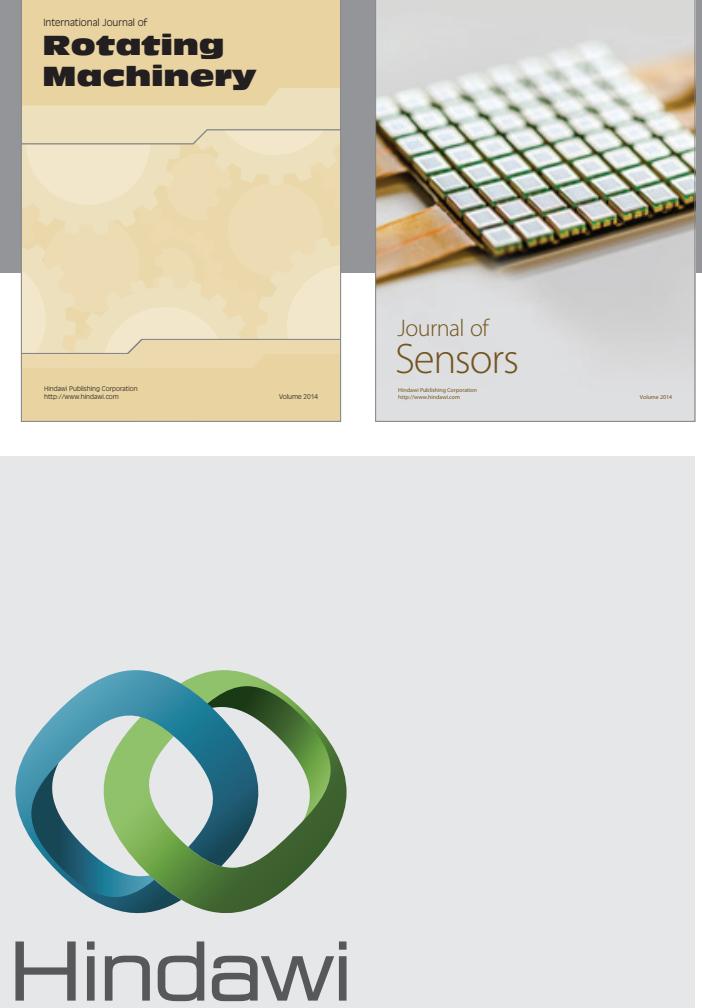

Submit your manuscripts at http://www.hindawi.com
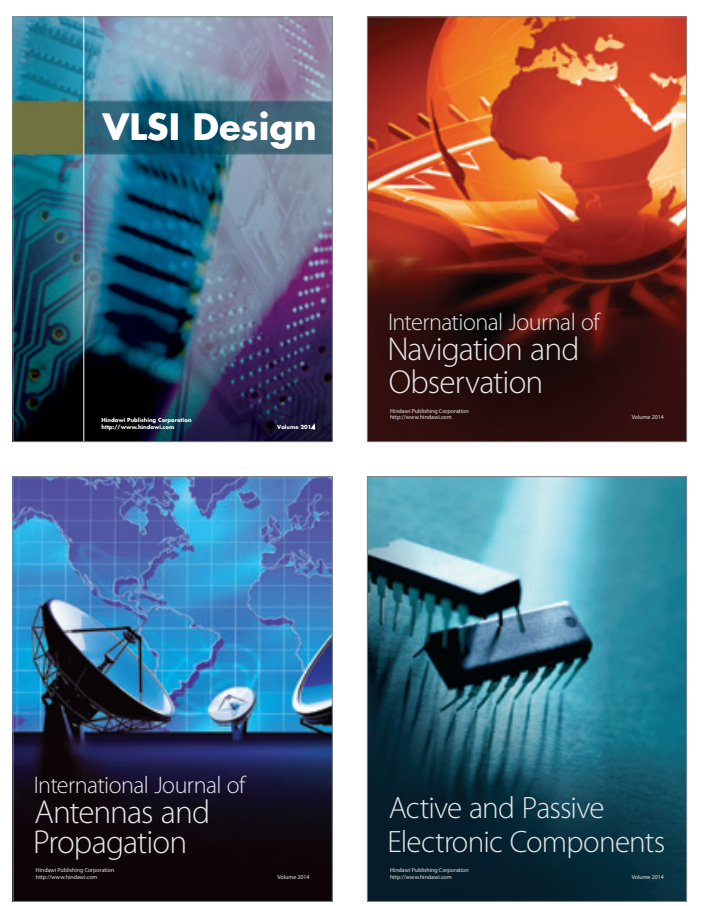
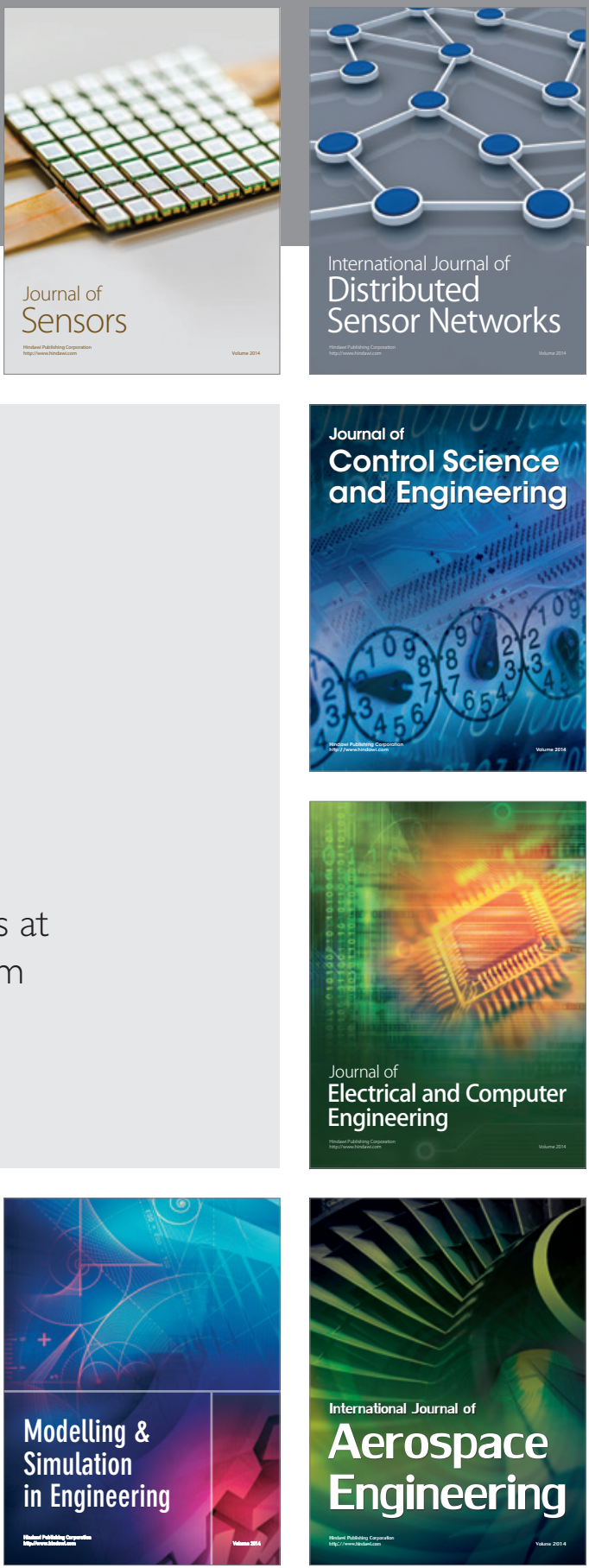

Journal of

Control Science

and Engineering
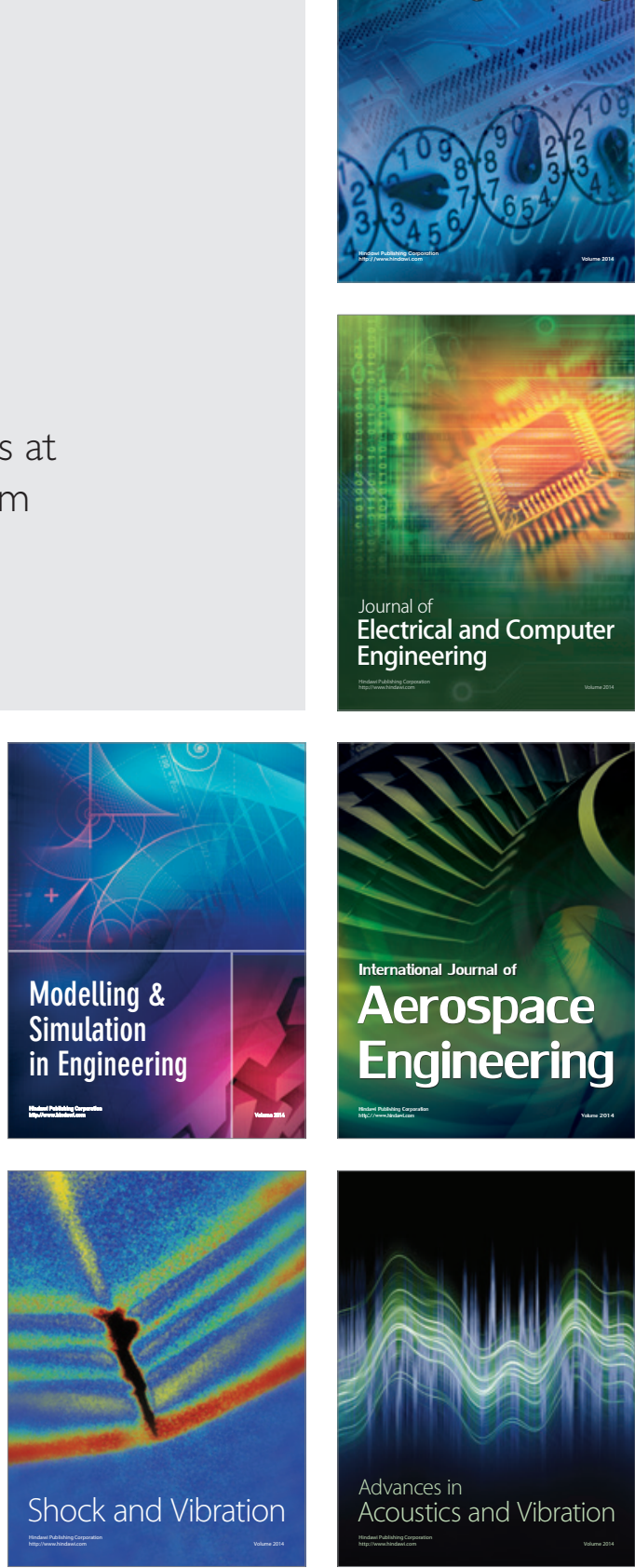